\title{
Suitability of the multiple case method when applied on dermatology and infectious diseases at the clinical stage of medical education
}

\author{
A Tärnvik, B Stenberg
}

\section{Citation}

A Tärnvik, B Stenberg. Suitability of the multiple case method when applied on dermatology and infectious diseases at the clinical stage of medical education. The Internet Journal of Medical Education. 2009 Volume 1 Number 1.

DOI: $\underline{10.5580 / \mathrm{dd} 2}$

\begin{abstract}
Background: By mimicking situations relevant to future work conditions, the multiple case method aims to trigger student interest in a subject and to induce familiarity with subject knowledge. Objectives: Our main aim was to assess the suitability of the multiple case method when applied at the clinical stage of medical education. Moreover, we wished to define the maximum group size with which students felt comfortable. Methods: Between 2001 and 2007, during 24 runs of a course in dermatology and infectious diseases, student assessments of the multiple case method were rated. Between 1993 and 2007, 1323 student evaluations were scrutinized for comments on group size. Results: On a 1-5 scale (1=value poor, $5=$ value high), student ratings of the multiple case method remained consistent at 4.4 to 4.7 . When the number of participants in the discussion groups was 18 - 25, no comments on group size occurred. When size increased to 26 - 33 participants, 4/605 (0.7\%) commented spontaneously that they would prefer discussing in a smaller group. At a size of $34-37,20 / 396(5.1 \%)$ expressed such a concern.
\end{abstract}

\section{INTRODUCTION}

Case methodology allows students to learn by studying realistic situations, thereby triggering their interest in a subject ${ }^{1,2}$. In education aimed at specific professional areas, students' future working conditions can be mimicked. Cases are usually derived from the experience of the teacher or design team, and, in contrast to problem-based learning, the case method relies strongly on a teacher or tutor with subject-matter expertise ${ }^{3,4}$.

Besides its merits in terms of student activity, a more practical advantage of case methodology is its compatibility with large student groups, implying that scheduled teaching time can be kept at a reasonable level. At the Harvard Business School, the case method is applied to groups as large as 50-60 students, and according to some institutions, group size may even be increased to $80-90,5$. It should be noted, however, that the feasibility of such high numbers may depend on the type of case study practised and also on special efforts taken to create an environment in which they feel comfortable ${ }^{6,7}$.

From classical case methodology, various modifications have been made, each responding to a specific educational situation. Such a modification is the multiple case method, an adjunct to classical lecture-based curricula ${ }^{8}$. The aim of the approach is to help students become familiar with knowledge already presented in lectures and written material.

In the present study, the suitability of the multiple case method was assessed. Between 2001 and 2007, student evaluations were rated and analyzed with regard to learning merits. In particular, we wished to know whether student satisfaction might fade with time or be persistent through the whole 6-year period. Moreover, a successive increase between 1993 and 2007 in the number of students attending our medical school enabled observations of tension due to large group size.

\section{METHODS}

The multiple case method was evaluated by students attending a course in dermatology and infectious diseases. The course comprised eight weeks in the $9^{\text {th }}$ semester of medical education at Umeå University in Northern Sweden. In 2000, the local curriculum of medical education had 
undergone revision towards more case-based studies, with a corresponding reduction of lectures. A 2-year preclinical and a 4.5 year clinical period were kept non-integrated. Along with lectures and multiple case sessions of the present course, students were scheduled for clinical placement at the unit of dermatology and the unit of infectious diseases of the University Hospital of Umeå. Within their placement periods, students received bedside teaching.

A lecture-case discussion approach was here applied to a number of issues, each of which comprised 2 to 6 hours of lecturing and assignments for a 1 to 4-hour (usually 2 hour) case session. Although most sessions were chaired by one clinical teacher, 3 out of 13 sessions involved two facilitators, due to a demand for widened subject expert knowledge. Altogether, 18 different facilitators were involved during the 6-year period, none of whom had undergone formalized education on the method.

At the very beginning of a course, the lecture/case discussion approach was explained and a suggestion on student and teacher behaviour during case sessions was presented. Before each session, students received handouts with a varying number of cases for individual preparation, as here exemplified.

A 54-year-old woman is hospitalized with a one-day history of high fever, sore throat, vomiting, and coughing. On admission, despite intake of paracetamol, her temperature is $40^{\circ} \mathrm{C}$. She is hoarse although not breathless and is suffering from impaired swallowing. Her oral cavity shows pharyngeal redness and her tonsils appear somewhat enlarged. Neck palpation shows bilateral tenderness and pulmonary auscultation shows slightly decreased breath on her basal right side. One day upon admission, the bacteriological laboratory reports the presence in blood culture of gram negative rods.

Figure 1. Typical example of the multiple case method applied on infectious diseases.

A young woman seeks attention at her primary health centre due to itching eczema. Her occupation at a hamburger restaurant includes preparation of food, washing-up and cleaning. Since high school and in winter-time in particular, her hands (back of hands and fingers) have been dry and chapped. Her present hand eczema appeared within two months of employment at the restaurant. She worries over her present way of life and future professional options. She would like to stay within food business and become an educated cook. She previously underwent shoulder and back tattooing and displays piercing in the wing of her nose, in ears and through her tongue and lower lip.

\section{Figure 1}

Figure 2. One of four cases included in a two-hour session on dermatology.

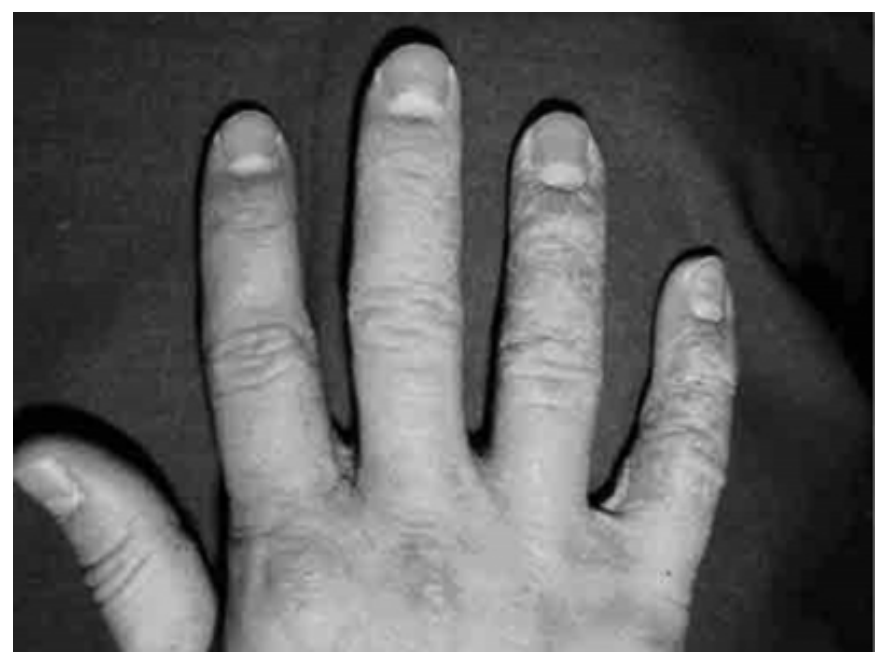

During each session, a student was called on to present the case, including analysis and suggested handling. The presentation was followed by a discussion, in which the teacher's role was restricted to time-management, encouraging student interaction and contribution with additional information on the case. In one session, the format was varied insofar as four students were called to discuss a case in front of their peers, followed by a general discussion. All sessions closed with the teacher giving her personal opinion and explaining what happened when the case occurred in reality.

Written evaluation forms, designed by the teachers in concert, were distributed at the beginning of a course and anonymously collected at the end of the course, after the final examination. Criteria for student rating were kept intact during the study period, as well as questions related to quality of the lecture/multiple case approach. Students were asked to give their view and comments on the organization of the course, on lectures/seminars and on teachers' attitudes. A question was formulated "If you were assigned the task of facilitating during the next run of the course, what changes would you like to do?"

A written test was performed as a final examination of each of 24 runs of the course in 2001 - 2007. In around twenty clinical scenarios, diagnostic and therapeutic considerations were asked for. 
During the period 2001 - 2007, groups attending the multiple case sessions varied from 24 to 37 students. To widen the base of student comments related to group size, we also scrutinized evaluations during the preceding 8-year period, when the multiple case method was used in an infectious diseases course with smaller group sizes (down to 18 participants).

For statistical analysis, comparison of the distribution of scores in different time periods (Table 1) was done using the Kruskal-Wallis test. Comparison of proportions (Table 2) was done by Chi-2 test.

Ethics approval: According to the Swedish law for research ethics (2003, revised in 2008, Swedish Government bill 2007/09:44), anonymous forms without sensitive personal data can be used without approval from a research ethics committee.

\section{RESULTS}

During the $2001-2007$ period, 779 students attended the case sessions. Of these, $629(80.7 \%)$ completed evaluation forms. When the educational value of the sessions was assessed on a 1-5 scale, a mean score of 4.6 was obtained (Table 1).

\section{Figure 2}

\begin{tabular}{|c|c|c|c|c|c|c|c|c|c|}
\hline \multirow{3}{*}{$\begin{array}{c}\begin{array}{c}\text { Time } \\
\text { period }\end{array} \\
\begin{array}{c}\text { From } \\
\text { August to } \\
\text { June }\end{array} \\
\end{array}$} & \multicolumn{9}{|c|}{ Students assessment of the educational value } \\
\hline & \multirow{2}{*}{$\begin{array}{l}\text { Group } \\
\text { size, } \\
\text { mean } \\
\text { (range) }\end{array}$} & \multicolumn{5}{|c|}{ score } & \multirow{2}{*}{$\begin{array}{l}\text { No of } \\
\text { sessions } \\
\text { per run of } \\
\text { course, } \\
\text { range }\end{array}$} & \multirow{2}{*}{$\begin{array}{l}\text { No of students } \\
\text { answering } \\
\text { I total number of } \\
\text { students }\end{array}$} & \multirow{2}{*}{$\begin{array}{l}\text { Mean } \\
\text { score }\end{array}$} \\
\hline & & $1^{*}$ & 2 & 3 & 4 & 5 & & & \\
\hline 2001-2002 & $\begin{array}{c}27.25 \\
(24-31)\end{array}$ & 0 & 0 & 2 & 30 & 53 & 13 & $\begin{array}{l}85 / 109 \\
(78.09 \%)\end{array}$ & 4.60 \\
\hline 2002-2003 & $\begin{array}{c}31.0 \\
(26-36)\end{array}$ & 0 & 2 & 8 & 40 & 50 & $10-11$ & $\begin{array}{l}100 / 124 \\
(80.6 \%)\end{array}$ & 4.38 \\
\hline 2003-2004 & $\begin{array}{c}30.25 \\
(29.32)\end{array}$ & 2 & 0 & 5 & 28 & 60 & $9-10$ & $\begin{array}{l}95 / 121 \\
(78.5 \%)\end{array}$ & 4.49 \\
\hline 2004-2005 & $\begin{array}{c}35.25 \\
(34-36)\end{array}$ & 0 & 0 & 5 & 44 & 74 & $9-10$ & $\begin{array}{l}123 / 141 \\
(87.2 \%)\end{array}$ & 4.56 \\
\hline 2005-2006 & $\begin{array}{c}36.0 \\
(34-37)\end{array}$ & 0 & 1 & 2 & 33 & 84 & $9-11$ & $\begin{array}{l}120 / 144 \\
(83.3 \%)\end{array}$ & 4.67 \\
\hline 2006-2007 & $\begin{array}{c}35.0 \\
(31-37)\end{array}$ & 0 & 0 & 3 & 23 & 80 & 9 & $\begin{array}{l}106 / 140 \\
(75.79 \%)\end{array}$ & 4.73 \\
\hline Total & $\begin{array}{l}32.46 \\
24-37)\end{array}$ & 2 & 3 & 25 & 198 & 401 & $9-13$ & $\begin{array}{c}6297779 \\
(80.7)\end{array}$ & 4.58 \\
\hline
\end{tabular}

$* 1=$ value poor; $5=$ value very high

Table 1. Student long-term assessment of the multiple case method when applied on infectious diseases and dermatology at the clinical stage of medical education

During the 2001 - 2007 period, the mean score of one-year intervals varied from 4.4 to 4.7 . When the distribution of scores was compared among different years, a significant difference was found only between the 2002-2003 and 2005-2006 intervals, the latter showing a higher score (p $<.05)$. Thus no decline of satisfaction occurred with time. On the contrary, long-term persistence in terms of student satisfaction was demonstrated.

In their comments several students expressed satisfaction without explanation, whereas others explained briefly why the lecture/multiple case approach was appreciated. The latter comments were collated. Merits in terms of efficient learning, stimulation of interest and encouragement of immediate reading were discerned.

\section{EFFICIENCY FOR LEARNING}

By covering a wide variety of issues, the lecture/multiple case approach helps student manage a voluminous course content. Case sessions offer rich opportunities for questions and discussion and for clarifying thoughts.

Citations found in student evaluations:

- "the approach is the most valuable moment of the course"

- "the approach is crucial to gain clinical insight"

- "through the case discussions I learned a lot"

- "the case discussions were great as a means of learning"

- "the approach is rewarding - provides opportunities to ask questions after reading"

- "the approach is a prerequisite for assimilation of such a comprehensive material in an 8-week period"

\section{STIMULATING WAY OF LEARNING}

By bringing students closer to real work settings, the approach stimulates learning. In case sessions, various aspects are introduced, such as ethics, genus, law and human relationships. The multiple case approach allows rich opportunities for such angles to appear. Maybe most rewarding, the approach was found to be enjoying.

Citations found in student evaluations:

- "the approach affords new angles" 
- "the case discussions worked and were more enjoying than were the lectures"

- "the case discussions helped me keep up the steam"

- "the case discussions varied widely in approach stimulating"

- "the case discussions motivate reading"

- "the approach is student-activating"

\section{ENCOURAGEMENT TO LEARN ALREADY FROM THE START OF COURSE}

By offering opportunities for work on cases applicable to various learning issues, the multiple case approach will encourage continuous reading, thus counteract a proneness to postpone reading till the time of examination.

Citations found in student evaluations:

The approach

- "implies that you will read continuously"

- "pushes me to read"

- "made me get something done"

- "encouraged me to keep up with the course"

- "encouraged me to read the material in advance"

- "made me feel well prepared for the final test"

Figure 3. Merits of the lecture/multiple case approach as illustrated by citations found in student evaluations

During the 2001 - 2007 period, group sizes successively increased from a mean of 27 students in the first interval to 35 students during the last interval. To widen the study, we included the preceding 8-year period, when the method was applied to a course restricted to infectious diseases. During the whole 14-year period, groups increased successively from 18 to 37 . We scrutinized all comments made in reply to questions on course organization in general and case discussion in particular. Comments specific to group size were not solicited, which means that all such comments were spontaneous. During the period, 1323 of 1602 students (82.6 $\%$ ) completed written evaluations at the end of course. Of these, $24(1.8 \%)$ commented that a smaller group size would have been preferable (Table 2). Of 322 students participating in groups of $18-25$, none commented on group size. At sizes of 26 - 33 students, 4 of $605(0.7 \%)$ students commented that they would have preferred to participate in a smaller discussion group. At a group size of $34-37,20$ of $396(5.1 \%)$ students delivered such comments.

\section{Figure 3}

Table 2. Relationship between group size in case discussion and occurrence of negative comments in student evaluations.

\begin{tabular}{|lcccc|}
\hline Group size & \multicolumn{2}{l}{ No of students completing evaluation } \\
& $\begin{array}{l}\text { Total no } \\
\text { No (\%) commenting that } \\
\text { a smaller group would } \\
\text { preferable }\end{array}$ & & \\
\hline $18-21$ & 96 & $0(0 \%)$ & 118 & $81.4 \%$ \\
$22-25$ & 226 & $0(0 \%)$ & 260 & $86.9 \%$ \\
$26-29$ & 322 & $3(0.9 \%)$ & 389 & $82.8 \%$ \\
$30-33$ & 283 & $1(0.4 \%)$ & 370 & $76.5 \%$ \\
$34-37$ & 396 & $20(5.1 \%)$ & 465 & $85.2 \%$ \\
\hline
\end{tabular}

The proportion of negative comments was significantly higher among students in groups of $34-37$ than in groups of any of the smaller sizes ( $<$ <.001). Up to a size of $30-33$, there was no significant difference among group sizes in proportion of negative comments, not even between a group size of size 18-21 and a size of 30-33 ( $\mathrm{p}=.35)$.

Some students preferred a smaller group to make the discussion more open and less exam-like, whereas others perceived that a large group size rendered the discussion chatty. Two students commented that the environment was favourable in spite of a high number (35 and 36, respectively) of students.

\section{CRITICAL COMMENTS}

Within groups of 29 to 37 students, concern was expressed with regard to large group size. Discussions became severely restricted and also less constructive. Students felt less comfortable.

Citations:

Our large group size made discussions

- "resemble examination rather than provide excellent learning opportunities" (29)* 
- "become less open" (29)

- "resemble high school test of home work" (36)

- "be somewhat chatty and less effective" (37)

- "be occasionally irritating, people questioning my points before I completed" (34)

- "less active since many students feel worried about their answers" (36)

* Size of group in which the commenting student participated

\section{ENCOURAGING COMMENTS}

Exceptionally, students expressed their feeling of a relaxed atmosphere in spite of large group size.

Citations:

Despite our large group, the atmosphere was

- "fine, not intimidating" (36)

- "relaxed" (35)

* Size of group in which the commenting student participated

Figure 4. Comments related to group size found in student evaluations.

On two occasions, when group size increased from a mean of 30 to 35 students, facilitators decided to divide the group in two, despite the increased work load. This signified that there was a concern from the facilitators about large group size.

A final examination of each of 24 runs of the course in 2001 - 2007 was performed as a written test. Ninety-eight percent of the students attended the test; the remaining students offered a new opportunity three weeks later. Reasons for absence were not asked for. The mean test score was $85 \%$, and more than $98 \%$ of the students achieved $70 \%$, a level set in advance as the limit required to pass.

\section{DISCUSSION}

Our results provided extended experience on case-discussion learning in general and the multiple case method in particular. Student satisfaction and test results were found to be consistently high during 24 runs of a course including more than one clinical discipline and a large number of facilitators. Thus no decline in students' rating occurred with time, indicating long-standing satisfaction with the method. Finally, the present results afforded some guidance regarding the upper limit of group size compatible with a relaxed learning climate.

The results lend support to previous successful reports on case discussion at the clinical stage of medical education. Two pieces of experience will be related here. At the Albert Einstein College of Medicine, Bronx, New York, faculty had made numerous efforts during eight years to modify a course in epidemiology and biostatistics, including change from large to small group lectures and a combination of the two, a change from multiple to single lecturer complemented by subject-specific expert panels, introduction of critical literature analysis in place of mock research activities, introduction of small-group seminars and an attempt to employ problem-based learning ${ }^{9}$. None of these approaches yielded success with respect to student evaluations. When the case discussion method was introduced, students' rating of the learning experience on a 1-5 scale increased from 3.0 to 4.0 , thereby elevating it from one of the least popular first-year courses into one of the highest rated courses. A second example comes from the Goethe-Universität, Frankfurt, where a standard course in practical dermatology had proven "to be a disaster" 7 . To change the curriculum, an interactive large-group case-based teaching approach was combined with small-group bedside teaching. In terms of student satisfaction and learning outcomes the approach was a success. Such a mixture of class-room learning and clinical placement with bedside teaching occurred also in the present course. In essence, our experience from consistent largescale use of the case method over an extended period is similar to these reports. The present study and the two reports cited relied mainly ${ }^{9}$ or partly ${ }^{7}$ on student evaluations, a measure that has been found to correlate with actual learning in terms of student performance on standardized final exams ${ }^{7,10,11,12}$.

Among the reasons behind student satisfaction with the case method is the triggering of interest, which is in line with the primary aim of the strategy. Another less obvious outcome of the method was its encouragement of reading already from the beginning of the course (Figure 3).

Owing to a government-directed graded increase of number of students attending our medical school during the present study period, we were able to estimate the optimal group 
size as perceived by students to afford a comfortable discussion climate. We believe that spontaneous negative comments in student course evaluations constitute an appropriate signal. At a student-group size of $18-25$, no students commented on group size. This relates closely to a favourable student response to the case-discussion approach, when implemented in epidemiology and biostatistics for groups of $20-24$ students ${ }^{9}$. During the first five years of implementation, the overall course evaluation score was around 4 on a $1-5$ scale, and students' narrative comments reflected "excitement and satisfaction with the teaching method" " ${ }^{9}$ In a dermatology course, 40 - 60 students were found to function well, although without comparison to other group sizes ${ }^{7}$. In that setting, however, two tutors were present to handle content and facilitation of the discussion, respectively.

In an extensive review of research on class size in higher education, large sizes were found to be detrimental for several reasons, including restricted opportunities for questions, passivity and inhibition of students' cognitive growth, and a reduced overall course satisfaction with the learning experience ${ }^{13}$. However, few investigations defined more precisely what was meant by large. Usually, a size of 15 - 25 students is considered small and 50 or more considered large ${ }^{13}$. Since an increase from 15 to 50 students would considerably reduce the demand of personnel resources, the importance of more precise observations is necessary. When restricting our discussion groups to 33 , less than $1 \%$ of the students expressed any concern on group size. At sizes greater than 33, however, $5 \%$ of the students spontaneously delivered negative comments and two facilitators chose to divide one group into two. We conclude that group size should not exceed 25 - 33 in case discussion according to the present approach. According to our experience, such a size will allow intense discussion yet remain small enough so that students feel free to talk and interact with both peers and the facilitator.

Several limitations of the present study are identified. One relates to the absence of comparison of the present lecturecase approach with a traditional lecture-based curriculum. Similar to the experience of Ochsendorf et al. ${ }^{7}$, however, a controlled comparison of the case-study teaching with the standard course was not found possible to pursue. The unified recommendation from a large body of our student evaluations has been to keep the present format intact, i.e., a combination of lectures and case-based discussions. A second limitation relates to the lack of concurrent observations on varying group sizes. Students' perception may vary from one decade to another. Moreover, the optimum group size was based purely on student perceptions, and, in wider application, would have to be balanced against other factors, such as educational needs and resources. Interviews with educators or semi-structured questionnaires could have been of benefit to further understand aspects related to group size. Thirdly, the present comparison of test results across different time periods might be questioned, due to possible differences among student groups and also because of a possible variation in difficulty of tests. This is a limitation which is less obvious in measurements of student satisfaction. Fourthly, this study was carried out at one institution. Other factors, especially cultural factors, may affect the optimum group size at other institutions in other countries.

In essence, the results of this study show that the casediscussion method, when applied in multiple case format on the clinical stage of medical education, is long-term persistent. Strong evidence of its effectiveness can be derived from student evaluations and consistent high learning outcomes. The suitability adds to previous experience ${ }^{6,7,89}$ which, together form a basis for suggesting the method for a variety of courses at the clinical stage of medical education. When weighing student preferences against resources, the optimal size of a discussion group lead by one teacher seems to be within the interval of 25 to 33 participants.

\section{References}

1. Christenson CR: Teaching by the Case Method (Cambridge, MA, Harvard University

Press), 1981.

2. Barnes LB, Christensen CR, Hansen AB: Teaching and the Case Method (Boston, MA,

Harvard Business School Press), 1994.

3. Engelberg J: Complex medical case histories as portals to medical practice and

integrative, scientific thought. Am J Physiol 1992; 263: S45S54.

4. Tärnvik A: Revival of the case method: a way to retain student-centred learning in a

post-PBL era. Med Teacher, 2007; 29: e32-e36.

5. Erskine J, Leenders MR, Maufette-Leenders LA:

Teaching with cases (Ontario,

Canada, Richard Ivey School of Business, The University of Western Ontario), 1998.

6. Bowe CM, Voss J, Aretz HT: Case method teaching: An effective approach to integrate the basic and clinical sciences in the preclinical curriculum. Med Teacher, 2009; 31: 834-841.

7. Ochsendorf FR, Boehncke W-H, Sommerlad M, Kaufmann R: Interactive large- 
group teaching in a dermatology course. Med Teacher, 2006; 28: 697-701.

8. Tärnvik A: Advantages of using the multiple case method at the clinical stage of

medical education. Med Teacher, 2002; 24: 396-401.

9. Marantz PR, Burton W, Steiner-Grossman P: Using the case-discussion method to

teach epidemiology and biostatistics. Acad Med, 2003; 78: 365-371.

10. Centra JA: Students ratings of instruction and their relationship to student learning.

American Educational Research Journal, 1997; 14: 17-24.
11. Cohen PA: Student ratings of instruction and student achievement: A meta-analysis of

multisection validity studies. Review of Educational

Research, 1981; 51: 281-309.

12. McCallum LW: A meta-analysis of course evaluation data and its use in the tenure decision. Research in Higher Education, 1984; 21: 150-158.

13. Cuseo J: 2006. The empirical case against large class size: Adverse effects on the teaching, learning, and retention of first-year students. Online www.brevard.edu/fyc/listserv/remarks/cuseoclassize.pdf accessed 29.01.2006 


\section{Author Information}

Arne Tärnvik, M.D.

Professor, Department of Clinical Microbiology, Umeå University

Berndt Stenberg, M.D.

Associate professor, Department of Public Health and Clinical Medicine, Umeå University 